\title{
SUPERFÍCIE DA LÂMINA FOLIAR DE PSYCHOTRIA NUDA (CHAM. \& SCHLTDL.) WAWRA, P. LEIOCARPA CHAM. \& SCHLTDL., $P$. STENOCALYX MÜLL. ARG. E $P$. TENUINERVIS MÜLL. ARG. (RUBIACEAE) ${ }^{1}$
}

Recebido em 17.03.93. Aceito em 29.09.95

\author{
Ricardo Cardoso Vieira ${ }^{2}$ \\ Doria Maria Saiter Gomes ${ }^{2}$
}

\begin{abstract}
RESUMO: (Superfície da lâmina foliar de Psychotria nuda [Cham. \& Schltdl.] Wawra, P. leiocarpa Cham. \& Schltdl., P. stenocalyx Müll.Arg. e P. tenuinervis Müll.Arg. [Rubiaceae]). São apresentados dados relativos à micromorfologia da superfície foliar de quatro espécies de Psychotria. O estudo foi realizado em indivíduos que ocorrem na Floresta Pluvial Tropical (Mata Atlântica). Atenção especial é dada ao tipo de cera epicuticular e da escultura da superfície dos estômatos, papilas e demais células epidérmicas.
\end{abstract}

Palavras-chaves: MEV, folhas de sombra, Psychotria, Rubiaceae.

ABSTRACT: (Leaf surface of Psychotria nuda (Cham. \& Schltdl.) Wawra, P. leiocarpa Cham. \& Schltdl., $P$. stenocalyx Müll.Arg. e P. tenuinervis Müll.Arg. [Rubiaceae]). Micromorphology characteristics of foliar surface of Psychotria specimens are presented. The material studied was collected from specimens which grow in Tropical Rain Forest (Mata Atlântica). Special focusing is concentrated on the epicuticular wax type, as well as on the sculpture of the surface of stomata, papillae and other epidermic cells.

Key- Words: SEM, shade leaves, Psychotria, Rubiaceae.

\section{Introdução}

O Parque Nacional da Tijuca compreende uma vegetação típica de mata pluvial tropical, encerrando grande número de espécies, e constituindo um dos últimos remanescentes da Mata Atlântica do Estado do Rio de Janeiro. Tendo em vista a destruição deste importante ecossistema e a escassez de informações referentes a esta vegetação, é indispensável que tais espécies sejam estudadas, dentre outros, sob o ponto de vista da micromorfologia foliar.

\footnotetext{
1 Apoio FUJB.

2 Departamento de Botânica, Instituto de Biologia, UFRJ, CCS, Bloco A, 21949-900 Rio de Janeiro, RJ, Brasil.
} 
O estudo das características morfológicas de superfícies foliares é de extrema importância, visto que tais características contribuem para a quantidade de luz absorvida ou refletida pela folha, para a defesa contra parasitas e patógenos e sobretudo para a magnitude da transpiração cuticular (Martin \& Juniper 1970). Além disso, tais estudos fornecem subsídios à taxonomia vegetal (Stace 1965; Saddi 1988).

No Brasil, encontramos poucas informações sobre a superfície foliar, sobretudo no que diz respeito à microscopia eletrônica de varredura. Dentre os representantes dos diferentes ecossistemas existentes no país, Salatino et al (1986) fornecem dados sobre a micromorfologia de superfícies foliares de espécies lenhosas do cerrado, assim como Vieira \& Machado (1992) para folhas de sol e de sombra.

Com o objetivo de ampliar o conhecimento da família Rubiaceae, uma das famílias mais representativas da Mata Atlântica, os autores realizaram o presente estudo, em adição a outros trabalhos já concluídos (Vieira 1986; 198611988; Vieira et al 1992).

Neste trabalho, são discutidos aspectos da superfície foliar de Psychotria nuda, P. leiocarpa, $P$. stenocalyx e $P$. tenuinervis, visando fornecer mais informações ao taxonomista e correlacionar alguns aspectos com o ambiente.

\section{Material e métodos}

As espécies em questão vegetam nas Matas do Jardim Botânico do Rio de Janeiro, Floresta da Tijuca (Mata Atlântica). As exsicatas de Psychotria nuda, P. leiocarpa, $P$. stenocalyx e $P$. tenuinervis foram depositadas no Herbário do JBRJ sob os números RB 273.446, RB 277.998, RB 308.546 e RB 316.536, respectivamente.

Tais plantas são encontradas no interior da mata pluvial tropical, fazendo parte da sinúsia arbustiva. Tal fato leva ao sombreamento de suas folhas, provocado pelas plantas dos estratos superiores. Pelas nossas observações, podemos afirmar que o sombreamento não é muito intenso, nem uniforme, em virtude da irregularidade da copa das árvores.

Para o exame ao microscópio eletrônico de varredura (MEV), folhas adultas, provenientes do quinto nó, foram previamente herborizadas. Em seguida, as folhas foram separadas em dois lotes. Um deles foi submetido a duas fervuras em clorofórmio, de 5 minutos cada, com a finalidade de remoção da cera superficial (Martin \& Juniper 1970).

De cada uma das folhas dos dois lotes, ou seja, folhas tratadas e não tratadas, foram retiradas porções do terço médio, de aproximadamente $1 \mathrm{~cm}^{2}$. Em seguida, os fragmentos foram montados em suportes próprios e metalizados com ouro, para observação ao microscópio eletrônico de varredura (JEOL 25-S-II).

\section{Resultados e discussão}

As folhas das espécies em questão, de consistência sub-coriácea e coloração verde-escura, apresentam forma lanceolada, base cuneada e ápice agudo. 
A análise da superfície foliar revela cutícula lisa na face adaxial de $P$. nuda e $P$. stenocalyx (Figuras 1 e 3) e na face abaxial das quatro espécies estudadas (Figuras 69). Entretanto, a epiderme adaxial de P. leiocarpa e P. tenuinervis mostra cutícula estriada, com estrias paralelas e contínuas sobre as paredes anticlinais e periclinais (Figuras 2 e 4). Detalhe da cutícula estriada está evidenciada na figura 5. Em seu trabalho sobre a epiderme abaxial das folhas na família Rubiaceae, Accorsi (1947) registra cutícula estriada em 81 espécies das 601 estudadas. No sentido de verificar a influência do ambiente na ornamentação da cutícula, Bergen (1904) e Dunn et al (1965) observaram cutícula lisa para folhas de sombra ou espécies mesófitas ou hidrófitas, enquanto que as estriações predominam em folhas de sol ou espécies de ambiente xérico. Nas espécies estudadas, que possuem folhas de sombra e organização de mesófitos (Vieira et al. 1992; Gomes et al. 1995), encontramos cutícula lisa e estriada, mostrando que os fatores ambientais podem ou não influenciar determinados caracteres.

Nas espécies em estudo, a cera epicuticular pertence ao tipo grânulos, segundo a classificação de Wilkinson (1979). Tais grânulos, de tamanhos variados, apresentam distribuição irregular na superfície foliar. Assim, algumas áreas estão desprovidas de ornamentação (Figuras 3 e 7), enquanto que em outras regiões observam-se pequenos agrupamentos de material ceroso (Figura 11).

O tipo de cera encontrado nas espécies de Psychotria não encontra respaldo na conclusão de Hallam (1970) de que as folhas de sombra apresentam cera em forma de plaqueta. Todavia, a pouca quantidade de cera vem de encontro às observações de Skoss (1955) que registrou maior quantidade de cera nas folhas de sol. Segundo Barthlott \& Wollenweber (1981), nas regiões desprovidas de ornamentação de cera, a deposição se dá de maneira contínua sobre a superfície foliar. Os autores afirmam que este parece ser o caso mais frequente para as plantas vasculares. Por outro lado, Martin (1964) e Juniper \& Jeffree (1983) admitem que, em folhas com alta incidência de flora micológica, os fungos secretam enzimas que são capazes de dissolver a cera epicuticular. Nas quatro espécies de Psychotria, observam-se hifas de fungos distribuídas pela superfície foliar (Figuras 2, 7 e 9). O ambiente no qual vegetam as espécies em questão proporciona condições adequadas para o estabelecimento da flora micológica, visto que a umidade relativa da Floresta da Tijuca é de $82 \%$ (Mattos et al. 1976) e a precipitação média anual fica acima de 2000mm (Vieira 1990).

Os estômatos, com distribuição somente na face abaxial (Figuras 6-9), são do tipo paracítico, com fenda predominantemente longa e estreita (Figuras 10-13). A cutícula das células anexas e estomáticas é lisa, sendo que em $P$. nuda, as células anexas, eventualmente, podem apresentar cutícula com estriações radiais ou concêntricas (Figura 10). Nesta espécie, frequentes vezes, observam-se verrugas arredondadas sobre a saliência cutinizada das células estomáticas (Figura 10).

A epiderme abaxial de $P$. leiocarpa, $P$. stenocaly $x$ e $P$. tenuinervis é caracterizada pela presença de papilas (Figuras 14 e 15). Tais apêndices epidérmicos, dotados de superfície ornamentada, são de menores dimensões em P. stenocalyx. Napp-Zinn (1988) atribui as seguintes funções para as papilas: proteção contra a perda de água pelos 


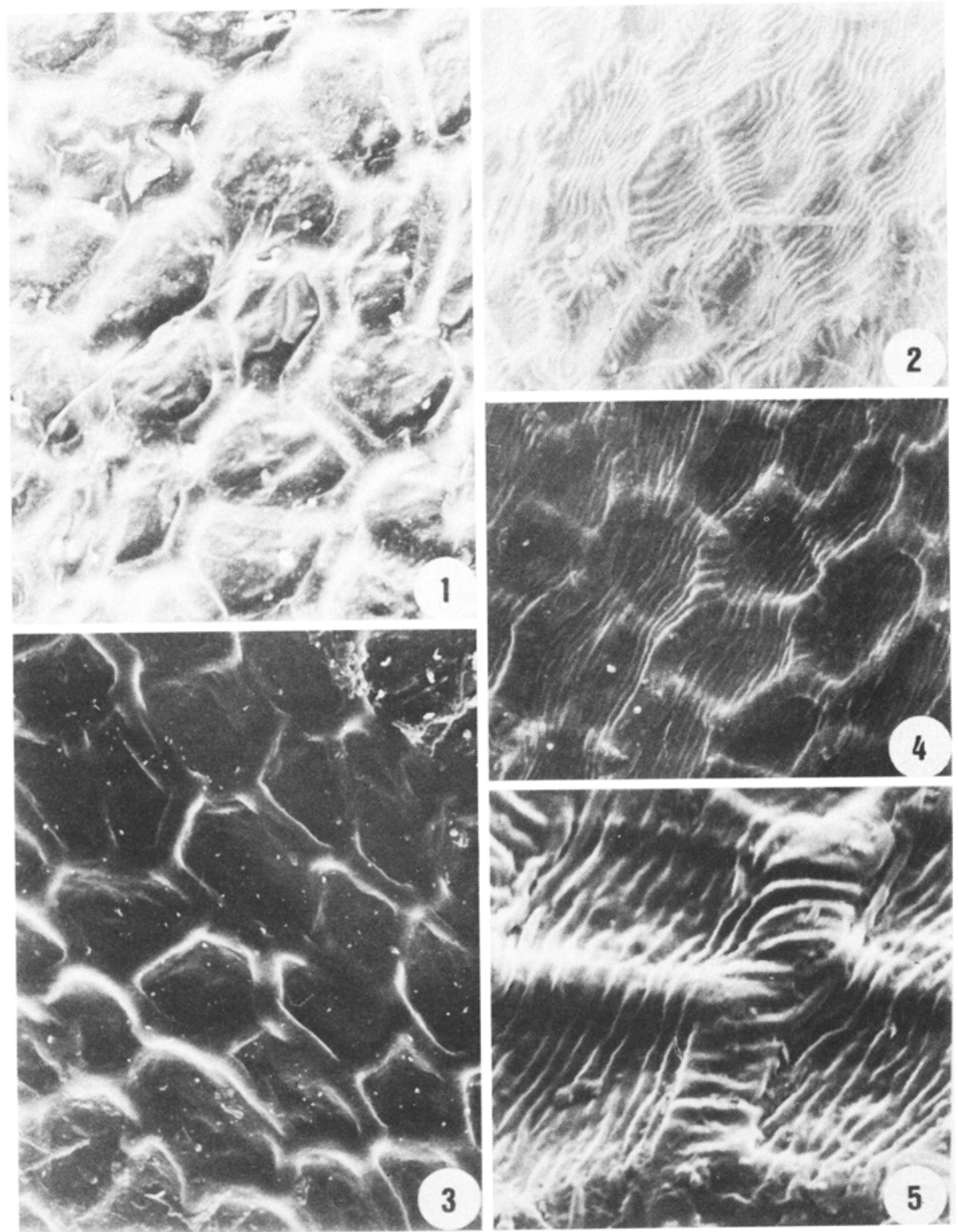

Figura 1-5. Eletromicrografias de varredura da epiderme adaxial de espécies de Psychotria. A cutícula é lisa em 1- $P$. nuda e 3- P. stenocalyx e estriada em 2- P. leiocarpa e 4- P. tenuinervis (700x). Detalhe da estriação de $P$. tenuinervis está evidenciada na figura 5 (1800x). 

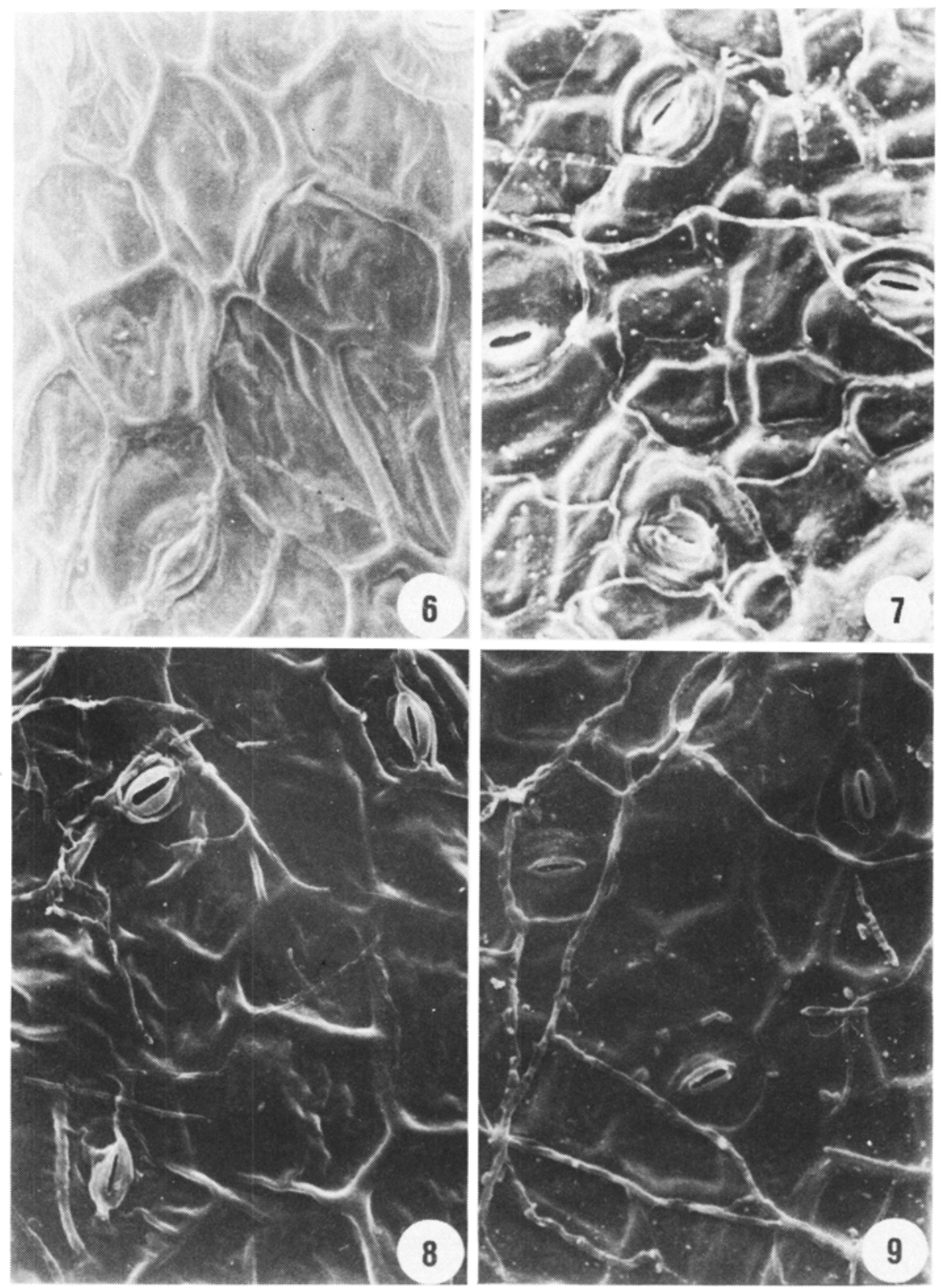

Figura 6-9. Eletromicrografias de varredura da epiderme abaxial de espécies de Psychotria. Cutícula lisa, cera do tipo grânulos e estômatos do tipo paracítico em 6- $P$. nuda, 7- $P$. leiocarpa, 8- $P$. stenocalyx e 9- $P$. tenuinervis (700x). 

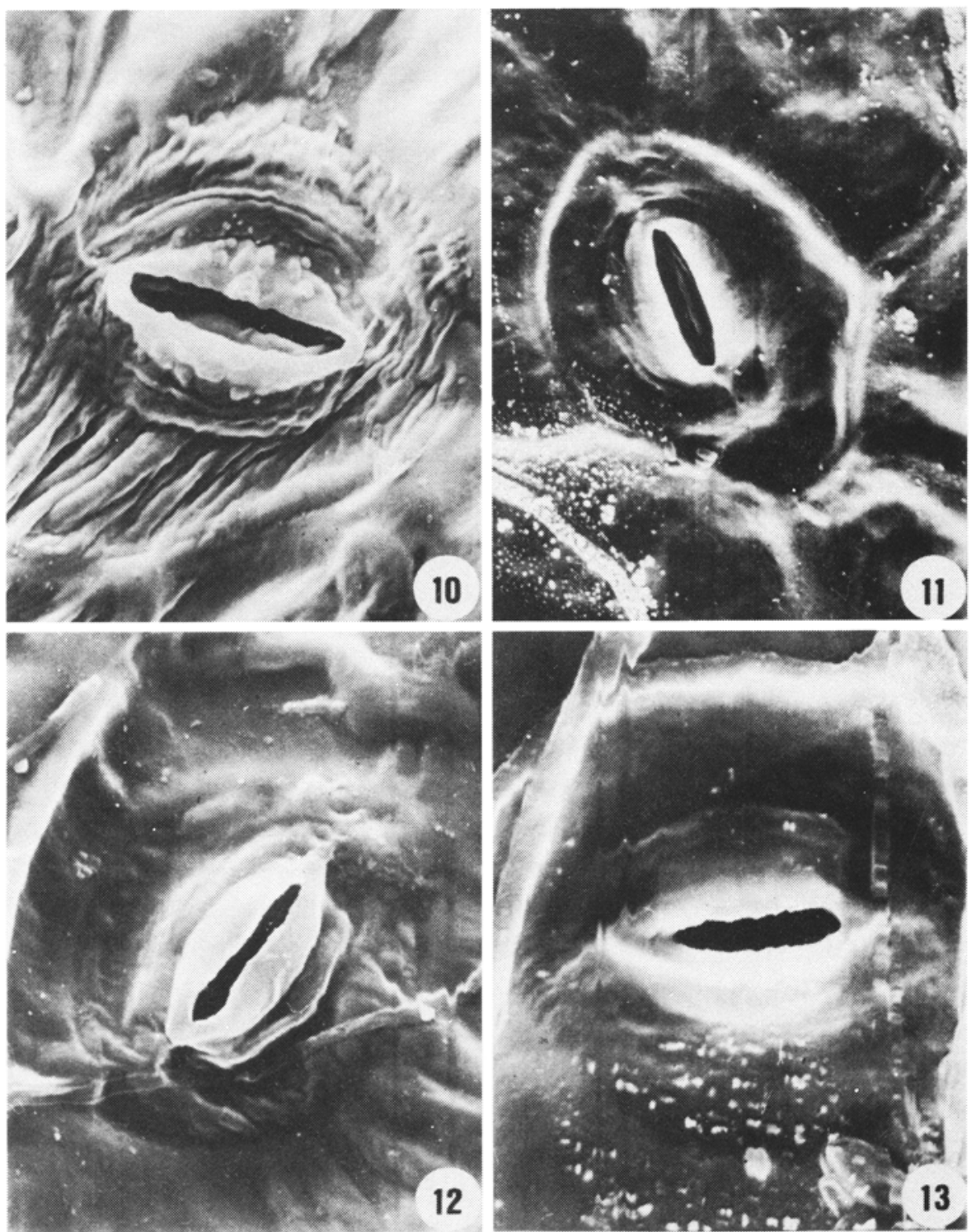

Figura 10-13. Eletromicrografias de varredura da epiderme abaxial de espécies de Psychotria. Detalhe dos estômatos com abertura longa e estreita em 10- P. nuda, 11- P. leiocarpa, 12- P. stenocalyx (2000x) e 13- P. tenuinervis (2900x). Em P. nuda (Figura 10) alguns estômatos mostram estriações na cutícula das células anexas e verrugas sobre a saliência cutinizada das células estomáticas. 

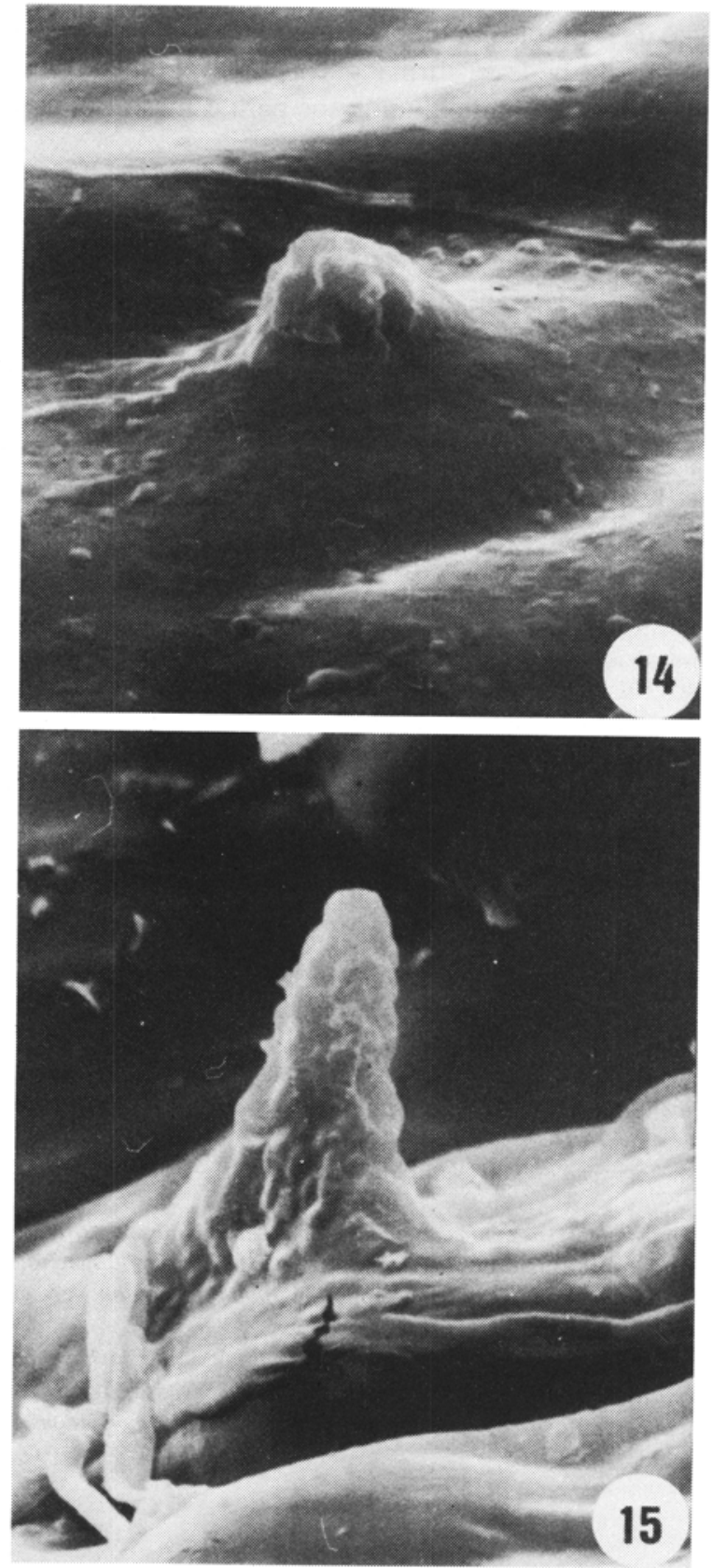

Figura 14 e 15. Eletromicrografias de varredura da epiderme abaxial de espécies de Psychotria. Detalhe das papilas de superfície ornamentada em 14- P. stenocalyx e 15- P. tenuinervis (2700x). 
estômatos e captação de estímulos luminosos. Pelo fato das folhas estudadas receberem luminosidade reduzida, pode-se afirmar que a provável função da epiderme papilosa seja a de convergir os estímulos luminosos para o mesofilo, atendendo, desta maneira, às necessidades da fotossíntese.

\section{Referências bibliográficas}

Accorsi,W. R. 1947. A ocorrência das células anexas dos estômatos na família Rubiaceae. Anais da E. S. A. "Luiz de Queiroz", 4: 421-436.

Barthlott, W. \& Wollenweber, E. 1981. Zur Feinstruktur, chemie und taxonomischen signifikanz epicuticularer wachse und Ahnlicher sekrete. Tropische und subtropische Pflanzewelt, 32: 1-67.

Bergen, J. Y. 1904. Transpiration of sun leaves and shade leaves of Olea europea and other broadleaved evergreens. Bot. Gaz., 38: 285-296.

Dunn, D. B., Sharma, G. K. \& Campbell, C. C. 1965. Stomatal patterns of dicotyledons and monocotyledons. Am. Midl. Nat., 74: 185-195 apud Metcalfe, C. R. \& Chalk, L. 1979. Anatomy of Dicotyledons. Oxford, Clarendon Press, v. 1., 276p.

Gomes, D.M.S., Mantovani, A. \& Vieira, R.C. 1995. Anatomia foliar de Psychotria tenuinervis Müll.Arg. e P. stenocalyx Müll.Arg. (Rubiaceae). Arq. Biol. Tecnol., 38 (1): 15-33.

Hallam, N. D. 1970. Growth and regenerative of waxes on the leaves of Eucalyptus. Planta, 93: 257-268. Juniper, B. E. \& Jeffree, C. E. 1983. Plant Surfaces. Edward Arnold, London, 93p.

Martin, J. T. 1964. Role of cuticle in the defense against plant desease. An. Rev. Phytopath., 2: 81-100.

Martin, J. T. \& Juniper, B. E. 1970. The Cuticles of Plants. Edward Arnold, 347p.

Mattos, C. C. L. V., Mattos, M. D. L. V. \& Laroche, R. C. 1976. Aspectos do clima e da flora do Parque Nacional da Tijuca. Bras. Fl., Rio de Janeiro, 7(25): 7-12.

Napp-Zinn, K. 1988. Anatomie der Blattes. Berlin, Gerbrudes Borntraeger, 764p.

Saddi, N. 1988. Micromorphological evidence in the genus Kielmeyera Martius (Guttiferae). Rev. Brasil. Biol., 48(4): 697-720.

Salatino, A., Montenegro, G. \& Salatino, M. L. F. 1986. Microscopia eletrônica de varredura de superfícies foliares de espécies lenhosas do cerrado. Revta. bras. Bot., 9: 117-124.

Skoss, J. D. 1955. Structure and composition of plant cuticle in relation to environmental factors and permeability. Bot. Gaz., 117(1): 55-72.

Stace, C. A. 1965. Cuticular studies as an aid to plant taxonomy. Bull. Br. Mus. nat. Hist.(Bot.), 4: 3-78.

Vieira, R. C. 1986. Diodia radula (Willd. et Hoffm.) Cham. et Schlecht. (Rubiaceae). Anatomia foliar. Rev. bras. biol., 46(3): 667-674.

Vieira, R. C. 198611988. Tocoyena bullata (Vell.) Mart. (Rubiaceae). Anatomia foliar. Rodriguesia, 64166 (38140): 33-39.

Vieira, R. C. 1990. Contribuição ao conhecimento da anatomia ecológica de Bauhinia radiata Vell. Dissertação de Mestrado, Universidade Federal do Rio de Janeiro, Rio de Janeiro, 203p.

Vieira, R. C. \& Machado, R. D. 1992. Superfície foliar de Bauhinia radiata Vell. em dois ambientes. Hoehnea, 19 (1/2): 111-116.

Vieira, R. C., Gomes, D. M. S. \& Ferraz, C. L. A. 1992. Anatomia foliar de Psychotria nuda Wawra e Psychotria leiocarpa Mart. (Rubiaceae). Hoehnea, 19(1/2): 185-195.

Wilkinson, H. P. 1979. In Metcalfe, C. R. \& Chalk, L. (eds) Anatomy of Dicotyledons. The Plant Surface. Oxford, Clarendon Press, p. 97-165. 